\title{
'It is a pivotal time for dental nurses'
}

\section{BDJ Team meets the British Association of Dental Nurses' new president, Fiona Ellwood.}

\section{Fiona's background}

Fiona has been instrumental in helping dental care professionals (DCPs) reach their full potential for many years. She has developed a successful training business in the Midlands and supports those providing pre-registration courses and the Oral Health Education Certificate. Fiona is a former examiner for the National Certificate, the Diploma and Oral Health Education award for DCPs; CEO of Dental Learning Curve; and director of mentoring and development for Dental Team Qualifications. She is a trained Mentor and a member of the Mentoring Development Team at $F G D P(U K)$, receiving a postgraduate certificate with distinction at level 7.

Outside of the teaching and development arena, Fiona is an FGDP(UK) Key skills assessor and a member of the FGDP editorial board; undertakes mentoring duties for others wishing to expand their field of work in the educational or dental arena and those looking to either improve their practice or make career decisions; and is a committee member of the National Oral Health Promotion Group.

Fiona has delivered short programmes to DF1s in relation to oral health and preventative care, mentoring in the workplace, train the trainer and improving work/life balance; and has presented on CQC, undertaken practice visits and delivered lectures on HTM 01-05, Information Governance and communication strategies. All of these support Fiona's role as a Quality Assurance Inspector for the GDC.

In addition to this, Fiona has acted as an external advisor to one of the leading dental schools and is a panel member involved in the Tooth Whitening Initiative. She continually strives to work with other skill sectors in providing joined up care for patients in care homes, and hospitals, in GP practices, schools and outreach areas.

Fiona is currently studying for her Master's degree and loves to read academic literature. She likes to spend time with her horses and at the gym unless she is watching her sons play sport.

\section{Fiona and BADN}

I joined the BADN when I first qualified as a dental nurse in 1986 and have been a member ever since. I have been a council member for a number of years and the East Midlands Coordinator, spending the year prior to becoming president as president elect and then finally becoming president. I have spoken at numerous events over the years and on a wide range of topics on behalf of BADN.

It is a great honour to be asked to represent the association and its membership, but something I never dreamt of being in a position to do.

\section{Representing the profession} Being president is a very varied role, which will see me representing the profession at all levels, attending sector meetings, providing professional opinions, speaking at events and maintaining existing relationships with other associations and members of the dental trade and media.

I am most looking forward to meeting new people and forging new professional relationships for the good of the association.

In my capacity as President I have attended the British Dental Hygiene and Therapy (BSDHT) conference, which was my first official engagement, and I was then invited to speak at the International oral care conference. I have been invited to attend the FGDP(UK) annual dinner and also the British Dental Conference and Exhibition.

BADN's Conference held during BDTA Dental Showcase in October was a huge success, with a record number of new and first time delegates and a wide range of speakers.

\section{Juggling roles}

I am fortunate that I have a good support network and I can be flexible in my working life. I still have an active role in the clinical arena, but much of my work is around developing educational courses for the dental team and outside of this is my mentoring work.

2014 has got off to a busy start, but looking ahead at events that are coming up I am sure it will become even busier, but I knew that when I accepted the role.

\section{BADN targets}

It is a pivotal time just now for the dental nursing profession, given that the first five-

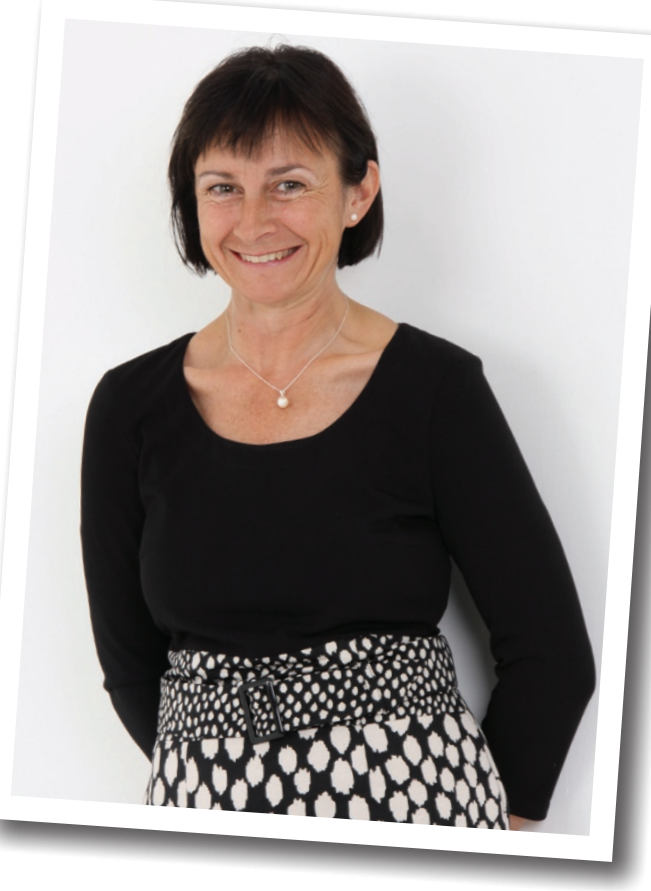

year cycle has passed and there is a lot to reflect upon, lessons to be learned and success to be celebrated. There are a number of issues and opportunities to consider during my time in office, but two of the key areas that much of my time will be devoted to are career pathways and skill-mix.

BADN's targets for this year and beyond are to continue to raise the profile of the dental nursing profession and strive to support their membership through times of change and with this in mind further grow the membership.

Dental nurses should join the BADN as it is the only professional association that represents dental nurses and it is proactive in informing and shaping the future for the profession. The BADN addresses a number of stakeholders in the dental arena on behalf of dental nurses and is made up of like-minded people who are passionate about the role.

\section{Dental nursing}

Dental nursing is a challenging and rewarding career with many different career pathways. It creates opportunities to further your education and acquire transferable skill sets, which can be applied across the different fields of dentistry and into other allied professions.

With additional and extended duties and a role in the direct access initiative, dental nursing is taking on a whole new meaning. It is a role that can be undertaken in general practice, in a hospital environment, in a community setting and in the armed forces.

www.badn.org.uk 